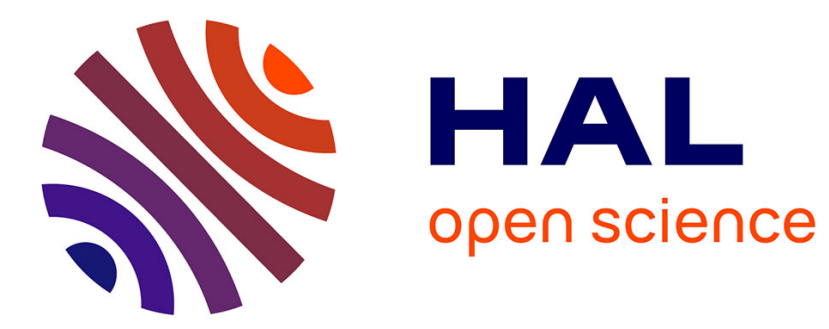

\title{
Iron-catalyzed coupling of three reactants
}

\author{
Guillaume Lefèvre
}

\section{To cite this version:}

Guillaume Lefèvre. Iron-catalyzed coupling of three reactants. Science, 2021. hal-03437179

\section{HAL Id: hal-03437179 \\ https://hal.science/hal-03437179}

Submitted on 19 Nov 2021

HAL is a multi-disciplinary open access archive for the deposit and dissemination of scientific research documents, whether they are published or not. The documents may come from teaching and research institutions in France or abroad, or from public or private research centers.
L'archive ouverte pluridisciplinaire HAL, est destinée au dépôt et à la diffusion de documents scientifiques de niveau recherche, publiés ou non, émanant des établissements d'enseignement et de recherche français ou étrangers, des laboratoires publics ou privés. 


\section{Vinyl boronates couple under mild conditions to two partners through carbon-carbon bonds}

\section{By Guillaume Lefèvre}

New methods that efficiently form carboncarbon bonds are welcomed by organic chemists if they run with high yield in few steps, introduce structural diversity, and if catalysts and co-reagents are required, are

as inexpensive and nontoxic as possible. Multicomponent reactions (MCR) that al-low reaction of three or more species in a single, convergent process introduce struc-tural diversity in one step. Efficient MCR-based processes can provide an easy access to the synthesis of molecule libraries, which is a valuable asset for the fabrication of families of drug-like compounds. On page 432 of this issue, Liu et al. (1) describe an efficient threecomponent reaction that di-functionalizes vinyl boronates by means of iron coordinated with a bulky phosphine li-gand. Grignard reagents (ArMgX, where Ar is an aryl group and $X$ is a halide) and alkyl halides (R9X) are partners in these transfor-mations that occur under very mild condi-tions (see the figure, top).

Iron-catalyzed cross-couplings have been extensively exploited in carbon-carbon bond formation processes developed during the past few decades [for a complete review, see (2)]. Those methods involve the creation of a covalent bond between two reagents through the reaction of an electrophile (typically an electron-poor derivative, such as an organic halide or pseudo-halide such as tosylate) with a nucleophile (typically an organometallic reagent bearing an electronrich metalated carbon atom-for example, an organomagnesium, an organozinc, or less often, an organoboron compound). The low cost and the environmentally friendly and biocompatible nature of iron make this metal particularly suitable for synthetic ap-plications in the development of products of pharmaceutical or biological interest (3). Many iron-catalyzed two-component crosscouplings have been reported, and some of them are now used on large preparative scales. However, the state of the art for ironmediated multicomponent transformations that involve organoboron derivatives has been particularly limited so far.

Vinyl boronates are particularly useful platforms in radical processes because of ease of generation of a-boryl radicals that have been used as MCR partners in nickel-photoredox catalysis, given their intrinsic enhanced stability (4). The methodology discussed by

\section{Iron mediates a three-component reaction}

Structural diversity can be achieved more rapidly if three reactants can form a single product in one step. Liu et al. report the difunctionalization of a vinylboron mediated by an iron catalyst under mild conditions.
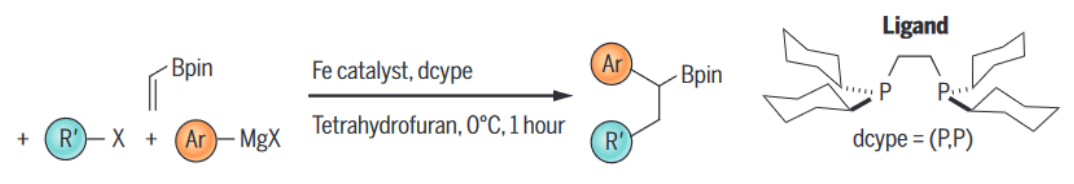

Double addition to vinyl boronates

The one-step reaction between a vinyl boronate (Bpin, vinylboronic acid pinacol ester), a Grignard reagent (where Ar is aryl), and an organic halide (where $\mathrm{R}^{\prime}$ is an alkyl group and $\mathrm{X}$ is a halide) is catalyzed by a bulky diphosphine-ligated iron complex (the structure of the dcype ligand is shown on the right).
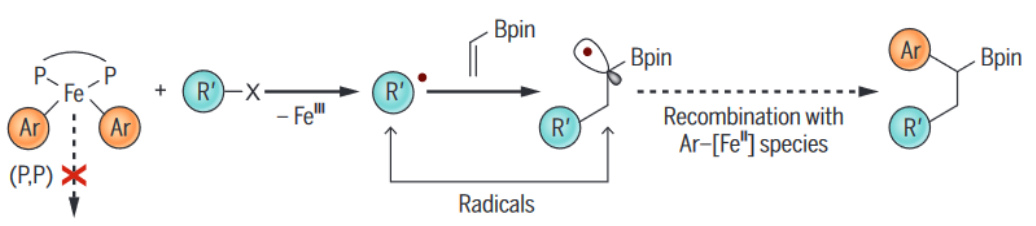

\section{Mechanistic steps}

Key steps of the transformation are shown. The bulky dcype ligand prevents binding of a second ligand that would form an inert complex. The activated alkyl radical reacts with the vinyl boronate to create a second radical, which undergoes a final redox step to complete the catalytic cycle.
Liu et al. relies on the successful association of a simple iron salt with an electron-rich bulky diphosphino [or $(P, P)$ ] ligand-in this case, 1,2-bis-dicyclohexylphosphinoethane (dcype)-and encompasses a large scope of reagents. This method also enables the use of fluoroalkyl halides as radical precursors, which leads to the incorporation of fluoro-alkyl chains in the final product as well as the development of annulation-arylation se-quences. These capabilities help address two outstanding challenges of iron-coupling ca-talysis. Such a versatility opens the way for a large number of synthetic combinations and makes a broad range of organic scaffolds ac-cessible in a single step.

Liu et al. performed thorough mecha-nistic studies using iron-57 Mössbauer spectroscopy as well as isolation and char-acterization of key intermediates by use of x-ray diffraction. These studies demonstrate the crucial role of the number of hydro-carbyl groups transferred by the Grignard reagent ArMgX onto the starting iron(II) complex [for a recent report on the bene-fits of physical-inorganic techniques in the elucidation of mechanistic facets of ironmediated processes, see (5)]. Depending on their coordination number, organoiron(II) species can display very distinct reactivi-ties, and their oxidoreduction properties

also strongly vary (6-9). Thus, mastering and exploiting the reactivity panel offered by the diverse coordination possibilities of organoiron species is often the key of a suc-cessful ironcatalyzed coupling sequence.

The catalytic process was initiated by a single-electron transfer between in situ generated bis-arylated complex $(\mathrm{P}, \mathrm{P}) \mathrm{Fe}$ " $(\mathrm{Ar})_{2}$ and the alkyl halide. As is often observed in ironcatalyzed two-component cross-coupling chemistry, this step ensures the formation of a free carbon-centered radi-cal. The latter does not undergo a fast re-combination with a transient organoiron, which is the usual final step in a classic two-component crosscoupling process. In-stead, this radical is added to the carbon-carbon double bond of the vinyl boronate (see the figure, bottom). The newly formed radical then forms the expected difunction-alized product after recombination with a

Chimie ParisTech, PSL University, CNRS, Institute of Chemistry for Life and Health Sciences, CSB2D, 75005 Paris, France. Email: guillaume.lefevre@chimieparistech.psl.eu 
mono-aryliron(II) intermediate, and a final redox comproportionation step completes the catalytic cycle.

Elucidation of the structure of the ac-tive species also showed that control of the chelation of the $(P, P)$ ligand (dcype in this case) to iron(II) is critical. This ligand helps selectively form unsaturated inter-mediates bearing only one dcype, unlike other (P,P) ligands with similar electronic properties, which formed saturated octahe-dral $(\mathrm{P}, \mathrm{P})_{2} \mathrm{Fe} "(\mathrm{Ar})_{2}$ species. Those species are unable to undergo a single-electron trans-fer with the organic halide, so no catalytic activity is observed.

The selective formation of species ligated by one dcype ligand originates in the high steric pressure brought by the cyclohexyl substituents of dcype, which hampers the inclusion of a second dcype in the iron coordination sphere. Thus, the judicious choice of this substituent limits the distri-bution of iron-containing intermediates to mono-dcype species and allows the crucial formation of the unsaturated bis-arylated $(\mathrm{P}, \mathrm{P}) \mathrm{Fe}^{\prime \prime}(\mathrm{Ar})_{2}$ after transmetallation with the Grignard reagent. Both steric and electronic effects of the dcype ligand contribute to the feasibility of this step.

The combination of a cutting-edge design of the interlocking of coordination prop-erties with stereoelectronic ligand effects governing the reactivity of this bulky iron-di-phosphine platform allowed Liu et al. to de-velop a new and robust synthetic strategy. It can potentially benefit various fields—such as synthesis of pharmaceuticals, materials, and pesticides-in the near future. Beyond this breakthrough in synthetic applications, this work also illustrates the importance of accurate mechanistic investigations in the field of iron catalysis. The distinctive and complex reactivity displayed by iron, involv-ing both one- and two-electron processes, as well as a broad range of oxidation and spin states should spur the development of new synthetic methods that will require a detailed understanding of the mechanistic aspect of these transformations (10).

\section{REFERENCES AND NOTES}

1. L. Liu et al., Science 374, 432 (2021).

2. I. Bauer, H.-J. Knölker, Chem. Rev. 115, 3170 (2015).

3. R. B. Bedford, P. B. Brenner, in Iron Catalysis II, E. Bauer, Ed. (Springer, 2015).

4. M. W. Campbell, J. S. Compton, C. B. Kelly, G. A. Molander,

J.Am. Chem. Soc. 141, 20069 (2019).

5. M. L. Neidig et al., Acc. Chem. Res. 52, 140 (2019).

6. R. B. Bedford et al., Angew. Chem. Int. Ed. 53, 1804 (2014).

7. S. L. Daifuku, J. L. Kneebone, B. E. R. Snyder, M. L. Neidig,

J.Am. Chem. Soc. 137, 11432 (2015).

8. Z. Mo, L. Deng, Coord. Chem. Rev. 350, 285 (2017).

9. L. Rousseau, N. Touati, L. Binet, P. Thuéry, G. Lefèvre, Inorg. Chem. 60, 7991 (2021).

10. A. Fürstner, ACS Cent. Sci. 2, 778 (2016). 